\title{
Meu, teu, nosso: reflexões sobre o conceito de cultura popular
}

HILÁRIO FRANCO JUNIOR

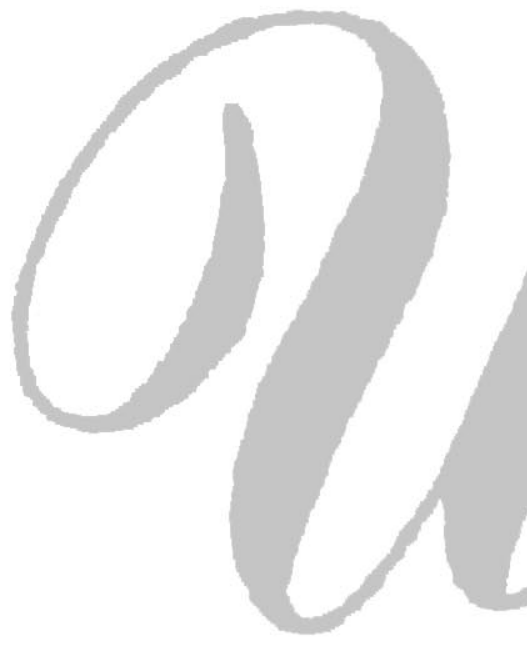

m dos temas que mais tem prendido a atenção das ciências humanas nos últimos tempos é o relativo à cultura popular. O que se deve entender exatamente por essa expressão? Quais as características dessa forma cultural? Quais as modalidades e implicações da relação entre ela e outros tipos de manifestação cultural? Qual a sua gênese e seu processo de transformação? Antropólogos, sociólogos, historiadores, folcloristas, lingüistas e psicólogos têm se debatido com essas e muitas outras questões. Tarefa dif́́cil, pelo fato daquele objeto de estudo estar muito próximo, direta ou indiretamente fazendo parte do cotidiano do pesquisador.

Chamam a atenção fenômenos como misticismo, magia, ritos demoníacos e saber esotérico, que não estão presentes apenas em sociedades do passado, ou do presente consideradas "primitivas", mas são claramente perceptíveis no mundo ocidental que pretensamente havia superado essa "fase" de seu desenvolvimento histórico. Em janeiro de 1989 , uma pesquisa revelava que $37 \%$ dos franceses acreditavam na existência do diabo, o dobro da porcentagem de 1968. E cerca de cinco milhões de pessoas naquele país acreditam viver, ao menos em certos momentos, sob uma influência demoníaca direta. Na Itália a situação é semelhante: $46 \%$ da população está convencida da existência de Satã.

Manifestações típicas de países latinos e católicos? Nos Estados Unidos uma sociedade internacional de feiticeiros luciferinos, que promove missas negras, agrupa dois milhões de adeptos, além de meio milhão na Inglaterra ${ }^{(1)}$. Manifestações de uma cultura “popular”, de gente atrasada? Os "possuídos" franceses não são, contudo, velhos camponeses mas sobretudo jovens citadinos. Os italianos crentes no diabo localizam-se mais no norte industrializado que no sul rural e comparativamente pobre. Os feiticeiros norte-mericanos e ingleses não são "imigrantes ignorantes", mas majoritariamente pessoas de certas posses e educação.

Acrescente-se a isso o desenvolvimento de vários fenômenos sócio-religiosos de massa considerados legítimos em suas sociedades - como os grupos evangelistas, a Teologia da Libertação ou o Islamismo radical - para entender o forte interesse dos estudiosos pela "religião popular". Os trabalhos se multiplicaram nos últimos anos, sem haver contudo consenso sobre o significado exato de "popular"(2). Por isso muitas vezes continua-se a pensar numa oposição erudito/popular, correspondente a racionalidade/afetividade e teorização/vivenciação, como se cada característica fosse exclusividade de um grupo social ou de um povo.

Postura que em suma prolonga a visão da antropologia do começo do século, que trabalhava com os conceitos de "mentalidade racional" e "mentalidade pré-lógica"(3). Prolongamento curioso, pois há muito as críticas e autocríticas a essa interpretação(4) foram se impondo, acompanhando as mudanças de relação entre países colonizadores e colonizados. Processo, aliás, interessante para se examinar as influências recíprocas entre política e intelectualidade: às vezes a antropologia fornecia argumentos para a descolonização, às vezes esta levava a antropologia a rever alguns de seus conceitos.

Legenda Aurea,

I, 161

A constatação do simplismo dos sistemas binários civilizado/primitivo, racional/irra- 

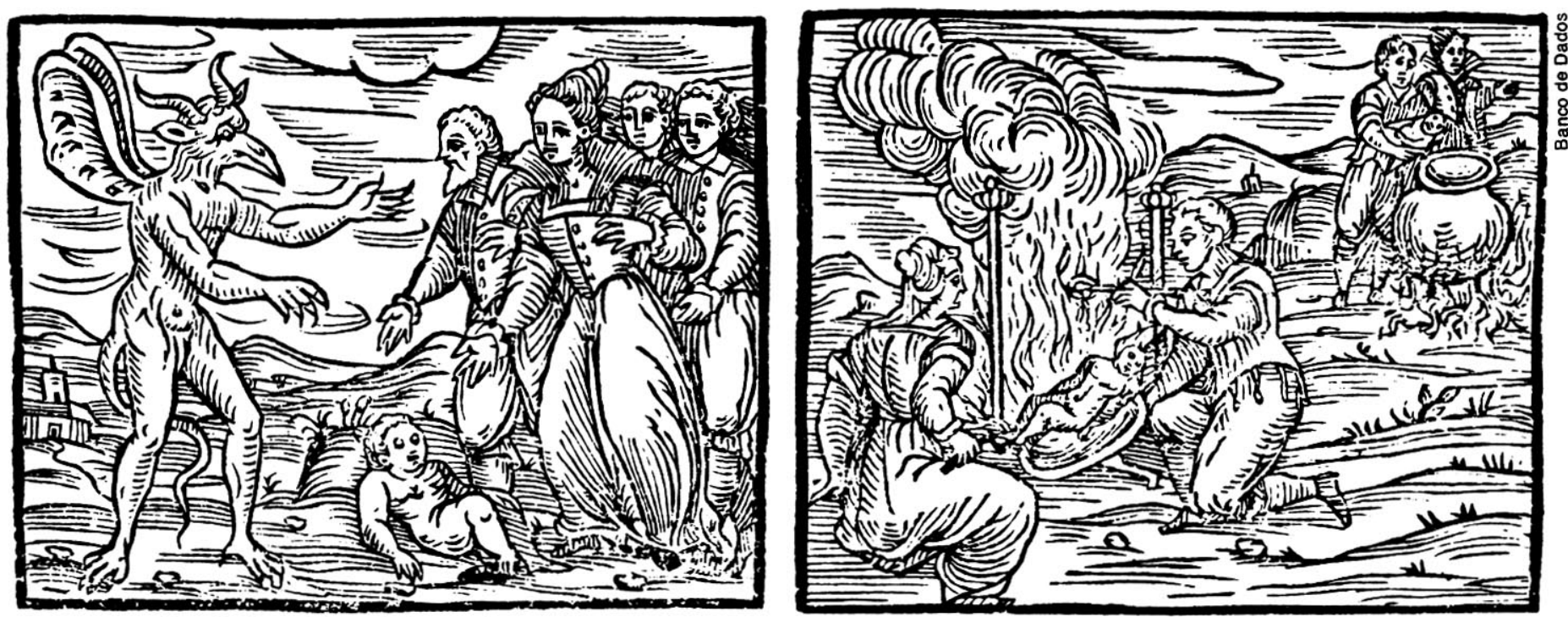

Gravuras medievais de práticas de bruxaria

cional, histórico/mítico, religioso/mágico e outros do tipo, provocaria importantes reflexões nas ciências humanas desta segunda metade do século. Acompanhando, aliás, a revisão epistemológica que ocorria em outras áreas do conhecimento, e que em suma revela os limites do modelo cartesiano. Como observou Blanché, um conhecimento dito objetivo é apenas aquele que é menos subjetivo que outro(5). A historiografia não ficou imune a tudo isso, e assumiu a subjetividade de seu discurso(6). Contudo, mais do que um simples acompanhamento de novas tendências científicas, esse passo revela a essência da historiografia.

De fato, ela não é apenas um instrumento de análise do passado, mas também uma produção cultural do seu presente, marcada portanto pelas necessidades e expectativas desse presente. Daí por que é preciso “observar o observador"'(7). O surgimento e desenvolvimento da chamada História das Mentalidades nas últimas décadas ilustra bem esse processo. As contradições da segunda metade do século $\mathrm{XX}$ - mais acentuadas do que as dos séculos anteriores devido ao poder controlador e destruidor que o homem alcançou sobre a natureza e sobre si próprio - tornaram necessária e criaram condições para uma análise do passado voltada para o homem interior. Sem desconsiderar a vida material, com a qual está estruturalmente articulada, é a história dos sentimentos que se torna o objeto central de estudo. As ansiedades, as angústias, os medos, as esperanças, os sonhos, as utopias passam a ser os interesses básicos do historiador.

Isso deslocou o enfoque da história religiosa tradicional, centrada nas instituiçōes e personalidades eclesiásticas: passou-se a considerar mais o sentimento religioso que a religião. Para minimizar a polarização erudito/popular, que contudo ele adota, Manselli lembra a "unidade do fato religioso"(8). No entanto, ainda esquece com freqüência que o ser humano é um todo no qual razão e emoção, eventos da realidade vivida externamente e da vivida oniricamente, estão sempre presentes ao mesmo tempo. Por isso propusemos que "religiosidade popular não é aquela que se identifica com um grupo social, ou que teve origem nele, mas sim aquela que nas suas manifestações popularizou elementos de diversas procedências"'(9).

Ao perceber as dificuldades em se analisar os fenômenos religiosos isoladamente, a historiografia passou a se preocupar com as questões culturais, mesmo porque "a religião popular é um momento essencial da cultura popular"'(10). Ou seja, os sentimentos religiosos fortemente enraizados não podem ser alcançados a não ser através de suas expressões culturais. Não somente uma cultura de elite, livresca, construída em alguns locais especiais por algumas grandes personalidades, mas também e sobretudo uma cultura dos campos, das praças, das tavernas, das estradas, cultura oral, anônima, na qual todos são elaboradores, receptores e transmissores. Cultura "popular" portanto. Para esse estudo o historiador recorre a um instrumental variado, emprestado do sociologo, do lingüista, do psicólogo, do folclorista, do antropólogo. E se vê assim envolvido nas águas agitadas da discussão sobre o conceito de cultura ${ }^{(11)}$. Mas percebe claramente então que cultura erudita e cultura popular não podem ser vistas como elementos opostos e impermeáveis.
HILÁRIO FRANCO JUNIOR É

professor de Historia Medieval do Departamento de História da

FFLCH-USP e autor de Peregrinos, Monges e Guerreiros -

Feudo-clericalismo em Castela Medieval (Editora Hucitec).

1 Le Nouvel Observateur, $n^{2} 1363$ dez./1990, pp. 5-6 e 13

2 F. A. Isambert, "Religion Populaire, Sociologie, Histoire et Folklore", in Archives des Sciences Sociales des Religions, 43, 1977, pp. 161-84 46 , 1978, pp. 111-33, resume os principais trabalhos.

3 Sobretudo L. Lévy-Bruhl, La Mentalite Primitive, Paris, Alcan, 1922; L'âme Primitive, Paris, Alcan, 1927.

4 M. Leenhardt, Do Kamo: Personne et Mythe dans le Monde Mélanésien, Paris, Gallimard, 1947; Les Carnets de Lucien Lévy-Bruhl, Ed. M. Leenhardt, Paris, PUF, 1949.

5 R. Blanche, La Science Physique et la Realité, Paris, PUF, 1948, p.13.

$6 \mathrm{~J}$. Le Goff, Pour un autre Moyen Age, Paris, Gallimard, 1977, p. 15; G. Duby, Entrevista a Custodia Domingues, in Jornal de Letras (Lisboa), 27/3/1990, p. 16.

$7 \mathrm{G}$. Duby, "Le Mental et le Fonc tionnement des Sciences Humaines", in L'Arc, 72, 1978, p. 92

8 R. Manseli, La Religion Populaire au Moyen Age, Paris, Vrin, 1975, p. 16.

9 H. Franco Junior, Peregrinos, Monges e Guerreiros, Săo Paulo. Hucitec, 1990, p. 41.

10 C. Prandi, "Religion et Classes Subalternes en Italie", in Archives des Sciences Sociales des Religions, 43 1977, p. 93.

$11 \mathrm{Cf}$. as muitas definiçठes repertoriadas por A. L. Kroeber e C. Kluckhohn, Culture: a Critical Review of Concepts and Definitions, Cambridge (Mass.). Harvard University Press, 1952. 
12 M. Bakhtin, A Cultura Popular na Idade Média e no Renascimento, Sảo Paulo, HucitecUnB, 1987.

13 C. Ginzburg, O Queijo e os Vermes, Såo Paulo, Companhia das Letras Os Andarilhos do Bem, São Paulo. Companhia das Letras.

14 A. Gurevich, Medieval Popular Culture, Cambridge-Paris, CUP-MSH 1988.

$15 \mathrm{M}$. Mullett, Popular Culture and PO pular Protest in Late Medieval and Early Modern Europe, Beckenham. Croom Helm, 1987.

16 Niveaux de Culture et Groupes So ciaux, Paris, Mouton, 1967.

17 J. Le Goff, "Culture Cléricale et Traditions Folkloriques dans la Civilisation Mérovingienne", in Niveaux de Culture, pp. 21-32; P. Burke, Popular Culture in Early Modern Europe. Londres, Temple Smith, 1978, p. 28: Mullett, op.cit., cap. 2.

18 A. Van Gennep, Manuel de Folklore Français Contemporain, 9 vols., $\mathrm{Pa}$ ris, Picard, 1937-58, I, 43

19 M. Certeau, D. Julia e J. Revel, "La Beauté du Mort. Le Concept de Culture Populaire", in Politique Aujourd'hui, dez./1970, pp. 12-4.

20 N. Wachtel, "L'Acculturation", in J. Le Goff e P. Nora (dir.), Faire de I'Histoire. Nouveaux Problèmes, Paris, Gallimard, 1974, pp. 143-4.

21 Burke, op.cit., p. 70.

22 Y. Lefevre, L'Elucidarium et les Lucidaires, Paris, Boccard, 1954: Gure. vich, op.cit. cap. 5 .

$23 \mathrm{H}$. Grundmann. "Hérésies Savantes et Hérésies Populaires au Moyen Age", in J. Le Gott (apres.), Hêrésies et Sociétés dans l'Europe Pré-Industrielle. Paris, Mouton, 1968, pp. 209-14: G. Leff, "Hérésie Savante et Hérésie Po. pulaire dans le bas Moyen Age", ibidem, pp, 219-23.

$24 \mathrm{~J}$. Le Goff, "Culture Cléricale et Traditions Folkloriques", in op.cit.

25 G. Duby, "La Vulgarisation des Modèles Culturels dans la Société Fêo. dale", in Niveaux de Culture, pp. 33 . 40.

26 G. Cocchiara, "Sopravvivenze Folkloriche nel Paganesimo Siciliano", in Preistoria e Folklore, Palermo. Sellerio, 1978 (ed. orig. 1964), p. 116: J.C. Schmitt, "Religion Populaire et Culture Folkiorique", in Annales E. S. C., 31, 1976, pp. 945-6.

27 Gurevich, op.cit., p. XV.
É verdade que o conceito de circularidade cultural defendido por Bakhtin ${ }^{(12)}$ e utilizado por exemplo por Ginzburg(13), Gurevich ${ }^{(14)}$ e Mullett(15) enfatiza as trocas culturais, mas resolve insuficientemente a questão por continuar a pensar apenas em dois pólos. Parece-nos preferível considerar a relação entre níveis de cultura e grupos sociais(16). Contudo nem sempre é possível, especialmente para períodos mais antigos ou de documentação mais lacunar, o estabelecimento minucioso e preciso dos segmentos sociais e da produção cultural de cada um deles, bem como das suas interações. Nesses casos, talvez se possa continuar a trabalhar com um recorte sociológico mais grosseiro - mesmo porque muitas vezes o corte social não corresponde ao corte cultural ${ }^{(17)}$ - desde que valorizando a área de intersecção, e não apenas a troca isolada de alguns fragmentos culturais. O que naturalmente altera o sentido de cultura "popular".

A utilização deste termo sempre foi problemática, pois, como apontou Van Gennep ${ }^{(18)}$, ele é ambíguo por ter três acepções: indica o que foi criado pelo povo; o que agrada ao povo independentemente de sua origem; o que é considerado grosseiro e ilogıco e está ligado às camadas inferiores da população. Mesmo se excluirmos esse último significado, cheio de preconceitos, a ambigüidade continua presente se a palavra for aplicada a uma certa parcela da população. Depois, como já se observou com razão, toda definição de cultura popular tem um componente erudito( ${ }^{(19)}$. Mas podemos atenuar esses dois problemas se pensarmos em cultura popular como aquela praticada, em maior ou menor medida, por quase todos os membros de uma dada sociedade, independentemente de sua condição social. Isto e, nessa hipótese cultura popular seria o denominador cultural comum, o conjunto de crenças, costumes, técnicas, normas, instituições, conhecidos e aceitos pela grande maioria dos indivíduos da sociedade estudada.

O termo perde assim sua forte conotação sociológica, para ganhar um forte sentido antropologico. No entanto continuam presentes nessa análise áreas culturais específicas, grupais, classistas, sociais, enfim, que se inter-relacionam exatamente porque têm um imenso repertório de pontos comuns. E é através dessa área de intersecção que determinados pontos podem migrar num sentido ou noutro, alargando essa zona de identidade grupal (étnica, religiosa, lingüística, artística, etc.) e de intermediação cultural (a partir da qual ocorrem eventualmente mudanças sociais). No seio de um mesmo grande conjunto histórico-geográfico, os processos de aculturação tendem a ser facilitados pela presença de várias similitudes entre suas diversas culturas populares. Mesmo entre sociedades distanciadas no espaço e nas suas trajetórias históricas, tais similitudes existem entre as respectivas culturas populares - devido ao substrato profundo da psicologia coletiva, a mentalidade - ainda que possam ser enormes as diferenças entre suas culturas de elite.

Em função disso, já se pensou mesmo, para a Europa medieval e moderna, na ocorrência de uma aculturação interna ${ }^{(20)}$. Ao menos para a Idade Média, porém, os contatos culturais elite-massa mostram que, mais do que uma aculturação, ocorreu uma difusão e reinterpretação de elementos sá́dos do núcleo comum da cultura popular. No contato com bizantinos e muçulmanos, por outro lado, deu-se o que Wachtel chamaria de "aculturação espontânea", sobretudo na Península Ibérica e na Sićlia, salvo curtos períodos de "aculturação forçada". É verdade que os resultados mais visíveis e espetaculares daquele primeiro processo - influência da arte bizantina, traduçōes da escola de Toledo, redescoberta ocidental do aristotelismo, adoção de conhecimentos científicos orientais, etc. - se deram em relação à cultura clerical, mas com reflexos também na cultura simples.

O contraste na intensidade de absorção daquele material cultural por parte dos vários grupos sociais deveu-se mais à presença de instrumentos diferenciados do que a valores, interesses ou expectativas divergentes. Por outro lado, a possibilidade de migração de uma parte daquele material da cultura clerical para a simples, e vice-versa, não se deveu à existência de "anfíbios culturais"(21), de indivíduos que por pertencerem aos dois ambientes realizavam as trocas culturais. Sem perceber aspectos familiares nos elementos culturais levados até ele, cada grupo social pouco teria assimilado. Existiam "anff́ios" porque havia uma área cultural comum, e não o inverso. Um bom exemplo disso temos na obra de Honorius Augustodunensis, na primeira metade do século XII, sobretudo no célebre Elucidarium, cuja popularidade decorria de seu recurso freqüente a dados e narrativas que sensibilizavam a maior parte de seus leitores e ouvintes por provirem da cultura popular ${ }^{(22)}$.

Desse ponto de vista, as áreas culturais específicas em cada sociedade deixam de ser vistas como auto-suficientes, como se era muitas vezes levado a pensar pelas análises tradicionais. Não se verificam influências diretas entre aquelas áreas, pois as adoções, adaptações, deformações e mesmo negações se dão a partir do material que é recolhido 
na cultura popular. Só se assimila, modifica ou critica aquilo que se entende ou se pensa entender. Aquilo que não é estranho. Aquilo que, enfim, faz parte do universo comum, da cultura de todos, da cultura popular, espécie de koiné cultural que fornece a matéria-prima trabalhada de forma própria por cada segmento social.

Da mesma forma que não se pode deixar de considerar as particularidades de cada expressão cultural, não se pode permitir que estas desviem nossa atenção do núcleo comum. A melhor análise é aquela que leva em conta tanto as áreas periféricas quanto a central, isto é, a dinâmica das relações entre elas. Por isso, por exemplo, é inadequado tentar distinguir heresias eruditas de heresias populares, e pensar que a maior parte dos grupos heréticos se formou a partir das prédicas de um indivíduo letrado e dotado de conhecimentos teológicos que lhe permitiam criticar a Igreja da época ${ }^{(23)}$. Toda heresia é definida como tal em relação a uma ortodoxia, em cuja formulação, por mais erudita que seja, entraram inúmeros componentes absorvidos da cultura popular ao longo de sua formação histórica.

Ou seja, heresia é uma seleção (do grego hairesis, “escolha”) de elementos culturais diferente daquela feita pela ortodoxia. Daí ser secundário para uma história cultural e dos imaginários (mas não para uma história sociológica) determinar a condição intelectual dos indivíduos que fizeram aquela seleção, heréticos ou ortodoxos. $\mathrm{O}$ francês Pedro Valdo e o italiano Francisco de Assis foram contemporâneos, eram de uma mesma origem socioeconômica, tinham espiritualidades comparáveis, mas para a Igreja um foi herege, o outro santo. A heresia cátara combatia a sociedade feudal e a Igreja romana, fazendo-lhes uma crítica que rejeitava muitos valores destas, mas que também revelava preocupações semelhantes equacionadas de forma diversa, caso da sexualidade, da pureza do clero, da salvação da alma. Se entre heresia e ortodoxia sempre existiu uma fronteira pouco clara, uma zona cinzenta, é porque esta correspondia à delimitação movediça entre cultura popular e cultura de grupos sociais.

Exemplo talvez mais elucidativo sobre a relação entre as áreas culturais temos na evangelização das massas camponesas medievais. Se o clero acolheu dados culturais pré-cristãos, difundidos no seio daquela categoria social, não foi apenas como estratégia de conversão, mas porque tais dados estavam presentes também no próprio ambiente cultural eclesiástico. É preciso sempre distinguir o cristianismo no seu papel de ideologia e no seu papel de religião. Em relação ao primeiro, a cultura folclórica era claramente oposta - e nesse caso aculturação e imposição ideológica tornavam-se um mesmo processo - e a utilização de fragmentos dela pelo cristianismo era uma forma consciente de dominá-la, fenômeno tanto do campo na época merovíngia(24) quanto dos mendicantes nas cidades dos séculos XIII-XIV ${ }^{(25)}$. Em relação ao segundo, cristianismo e folclore se confundiam, faziam parte de um mesmo conjunto de concepções e sentimentos, daí uma inconsciente identificação profunda ${ }^{(26)}$.

Por isso a definição de Gurevich - cultura popular medieval é "a visão de mundo que emerge da complexa e contraditória interação entre o reservatório do folclore tradicional e o cristianismo"'(27) - precisa ser retocada em dois pontos. Inicialmente seria fundamental explicitar que a "contradição" da interação cultura folclórica-cristianismo é apenas um aspecto dessa relação. Depois, seria interessante marcar o caráter de nãoidentificação sociológıca do termo "popular'. Como lembra mesmo o grande medievalista russo, o uso de ervas por parte da "medicina folclórica" era aprovado pela llustração de Poty para o livro Assombraçóes no Velho Recife, de Gilberto Freyre 
Igreja se acompanhado por preces e condenado se acompanhado por encantações(28). Isto é, a necessidade do ato mágico era aceita por todos - portanto dado da cultura popular no sentido que atribuímos à expressão -, apenas as modalidades dele diferiam da cultura clerical (preces) para a cultura vulgar ("encantações"). O mesmo, aliás, poderíamos constatar quanto às festas, às peregrinações, ao culto aos santos, aos ritos, ao calendário, às práticas agrícolas, etc.

$\mathrm{Na}$ denominação das áreas culturais específicas, deve-se evitar adjetivações que decorram de um referencial social (elite/massa), político-ideológico (hegemônica/subalterna) ou técnico (letrada/oral), todos suscetíveis de transformações históricas mais ou menos rápidas que dificultam a análise. O par "erudita/folclórica" é válido, ainda que tenha uma conotação muito literária e acadêmica no primeiro termo (erudire $=$ instruir, eruditio $=$ ensino, vindos de ex, partícula negativa, e rudis, inculto, grosseiro) e se ressinta de uma certa acepção pejorativa do segundo. Talvez seja preferível assim "sofisticada/simples". Esses níveis culturais obviamente são, como também no caso da adoção de alguma das outras nomenclaturas, definidos um em relação ao outro. De acordo, portanto, com os parâmetros da sociedade estudada, e não por comparação com outros períodos ou sociedades. Não se pode pensar em "sofisticada" como sinônimo de lógico: um pajé indígena, um monge medieval ou um intelectual contemporâneo não são necessariamente mais racionaıs que os demais índios, que os leigos ou que os operários. São apenas especialistas em certas técnicas e conhecimentos considerados válidos pelo conjunto da sociedade. Trata-se do domínio aperfeiçoado (do grego sophistikós, argumentar de forma sutil e refinada) de um certo código, que os simples (simplex, formado de um único elemento) conhecem apenas superficialmente. Trata-se, portanto, de "eficácia simbólica".

No caso particular da Idade Média - ao qual nos prendemos por questão de especialidade -, além do núcleo central da cultura popular, é melhor falarmos em cultura clerical e cultura vulgar. A primeira expressão é usual na historiografia medievalística, pois providencialmente tem o duplo sentido de "eclesiástica" - e esse grupo social dominou a cultura sofisticada até pelo menos o século XII - e de "letrada", acepção que a palavra ganha desde fins do século XIII, quando cresce o segmento laico alfabetizado. Dessa forma, a expressão contempla ainda as mudanças sociais do período. Pela mesma razão, propomos cultura "vulgar" ao invés de "laica", pois, como já lembramos, a distinção social clérigo/leigo não correspondia a uma distinção cultural. Ademais, "vulgar" era palavra usada pelos próprios medievais para indicar algo diferente de clerical, sobretudo no domínio lingüístico - as falas vulgares, vernáculas, diante do latim -, o que justifica ainda mais o uso da expressão, já que aquela cultura (como a popular) era essencialmente oral.

Devido a essa oralidade básica das sociedades pré-industriais, no estudo da cultura popular delas, um papel central deve estar reservado ao mito. Sendo talvez o elemento cultural mais próximo da mentalidade, o mito sempre foi a forma privilegiada de uma sociedade arcaica enunciar e apreender a essencialidade do Universo. E por isso é um elo de ligação entre o homem e o cosmos, fundindo-os de tal maneira que ambos se tornam por sua vez entidades míticas. Ao estabelecer assim palavras, gestos, atos, eventos, pensamentos e sentimentos arquetípicos, porque colocados na origem dos tempos, o mito funciona como modelo de comportamento. Para os homens que o vivenciam, mito é registro de um passado indefinido e guia tanto para o cotidiano quanto para o transcendental a serem experimentados no presente e no futuro.

Para aquele que vive em uma cultura de forte presença mítica, o mito é história e a história é mito, o que estabelece certa harmonia entre o Modelar e o Vivido. Para o historiador, o antropólogo e o psicólogo, o mito é expressão dos comportamentos da sociedade que o cria, o recebe, o adapta, o transmite: o mito está na história e a história no mito, o que pode revelar os valores profundos da comunidade analisada. Seja para quem o vivencia, seja para quem o estuda, mito é forma de conhecimento. Construfdo a partir da intuição, da observação e da analogia, ele é um discurso (mythos = narrativa) metafórico globalizante sobre as esferas divina, natural e humana de/para/sobre cada sociedade pré-industrial.

Ao usar essa linguagem de transferência de sentido, ele não deixa de proceder por diferenciações, oposições, comparaçōes e correlações, como todo pensamento lógico. Ele não é insensível às contradições e às impossibilidades, como pensava Lévy-Bruhl, mas pertence a uma lógica diversa da ocidental contemporânea, a do "pensamento selvagem" conceituado por Lévi-Strauss ${ }^{(29)}$. Essa diferença em relação à nossa lógica deve-se a seu forte conteúdo emotivo - "o mito é sentido e vivido antes de ser inteligido e formulado", observou Leenhardt ${ }^{(30)}-$, o que não exclui porém o elemento racional: este 
e o mítico convivem, ainda que historicamente em certos momentos haja a predominância de um aspecto em detrimento do outro. Para Cazeneuve, "as características do pensamento mítico permanecem presentes sob o terreno da mentalidade lógica e fazem parte da natureza humana'(31).

Cada mito é totalizante no sentido de apresentar todos os aspectos das relaçóes entre os homens, e entre estes e o cosmos, aquilo que o pensamento analítico chamaria de político, econômico, social, filosófico, científico, religioso, mágico, etc. Mas isolado, cada mito mostra apenas fragmentos daquela globalidade (ainda que cada fragmento sob todas as suas facetas), que é recuperada pelo conjunto dos mitos de uma sociedade, a mitologia. Pode-se talvez dizer que mito é eixo paradigmático por apresentar várias versões, e mitologia é eixo sintagmático por ser associativa. Desta forma, um estudo a respeito deve considerar essa dupla característica, examinando as diversas versões do mito analisado - diz Lévi-Strauss que um mito é o conjunto de suas variantes ${ }^{(32)}-\mathrm{e}$ as articulações desse mito específico com outros da rede mítica na qual ele se encontra inserido.

Ao contrário do sentido que ganharia nas sociedades industrializadas, nas demais, antigas e atuais, o mito é uma realidade viva e influenciadora do comportamento individual e coletivo. Alexandre Magno empreendeu a conquista do Oriente tanto pelas condições materiais de então quanto por causa de Aquiles e da Iltada. Na sociedade européia medieval a hierarquia entre os sexos, com todas suas decorrências práticas, estava baseada não como simples justificativa mas como realidade sociopsicológica, no modelo de Adão e Eva. A descoberta e os primeiros tempos da colonização da América atualizavam e concretizavam por parte dos europeus a antiqüíssima busca do Paraíso Perdido: Mas na própria América antes mesmo da chegada dos colonizadores, certos grupos, como o dos tupinambás, sonhavam com uma idade de ouro. Nas sociedades tradicionais do Pacífico sul atual, a expectativa messiânica determinava novas relações sociais internas e externas.

Como todo conhecimento, o mito pretende ser uma forma de controle sobre a realidade externa e interna do homem. Ao dar certa organização e harmonia a estas realidades, o mito encontra para o homem um lugar no Universo, constrói algumas certezas, acalma a angústia de viver. Por isso, pondera Andre Akoun, mito e ideologia cumprem a mesma função, apenas um utiliza uma narrativa cheia de coisas sensíveis, seres estranhos, animais, plantas, minerais, enquanto a outra recorre a um discurso pleno de entidades abstratas ${ }^{(33)}$. E, pode-se acrescentar, ambos partem de um modelo de tempos imemoriais que pode ser recuperado através de determinados ritos. A conhecida fórmula "mito é palavra, rito é ação" é aplicável à ideologia, desde que se lembre da especificidade dos seus ritos.

Como todo conhecimento, o mito é desgastado pela história, pelas transformações do enquadramento cultural do qual ele tinha sido ao mesmo tempo síntese e matriz. Nesse momento ele perde sua eficácia simbólica, esgota-se como manancial de especulações e guia de condutas, e subsiste apenas como tema literário e artístico utilizado livremente por estar a partir de então mais no domínio da individualidade do que no da coletividade. Assim como ocorre com a ideologia, o mito só é visto como tal ou por seus críticos ou quando foi superado. Para sociedades nas quais ele está presente de forma viva e atuante, o mito ajuda a estabelecer a identidade grupal, constitui a visão de mundo da comunidade. Naturalmente, para os estudiosos não há obstáculo no fato do conceito de mito não ser interno à sociedade estudada, pois se trata de um instrumental de análise que permite se compreender aspectos de um grupo humano ocultos dele mesmo. Como ocorre, aliás, com boa parte dos conceitos utilizados pelas ciências humanas.

Esse processo de recusa à própria conceituação aparece claramente, por exemplo, no cristianismo medieval. Ele rejeitava as "quimeras" pagãs, as "superstições", os "mitos" enfim, sem perceber - e nem poderia ser diferente, pois toda interpretação mítica do mundo mitifica todo o Universo, não havendo espaço para se perceber enquanto tal - que ele próprio tinha uma mitologia. Mas, curiosamente, "sob muitos aspectos o cristianismo salvou a mitologia: dessacralizou-a de seu conteúdo pagão e ressacralizou-a com elementos cristãos, ecumenizando-a"(34). Ernst Cassirer já percebera que toda religião está indissoluvelmente conectada com e penetrada por elementos míticos ${ }^{(35)}$. Apesar de por muito tempo ter sido problemático aplicar-se o qualificativo "mítico" a um relato religioso, hoje se concorda que "o mito é verdadeiro, que ele é uma expressão verdadeira da experiência religiosa"(36).

Porém, o estudioso só tem acesso à mitologia da sociedade estudada no caso daquelas chamadas de "primitivas contemporâneas". Em relação às do passado, o acesso ao material mítico se dá de duas formas: ou através de registros literários e artísticos que
31 J. Cazeneuve, "Actualité des Mythes", in A. Akoun (dir.), Mythes et Croyances du Monde Entier, 5 vols., Paris. ces du Monde Entier, 5 vols.
Lidis-Brepols, 1985, V, 349.

32 C. Lévy-Strauss, Mythologiques, 4 vols. Paris, Plon, 1964-71.

33 Akoun, op.cit., I,14.

34 J. Souza Brandåo, Mitologia Grega, 3 vols. Petropolis, Vozes, 1986, I, 33. vols., Petropolis, Vozes, 1986, 33: cf. J. Seznec, "Moyen Age et ReAntiques", in Y. Bonnefoy (dir.), Dic tionnaire des Mythologies et des Re ligions des Sociêtés Traditionnelles et du Monde Antique, 2 vols., Paris, Flammarion, 1981, II,129.

35 E. Cassirer, An Essay on Man, New Haven, Yale University Press, 1970. p. 81 .

$36 \mathrm{~J}$. Goetz, "Mythe", in M. Viller et alii (dir.), Dictionnaire de Spiritualite, 15 vols., Paris, Beauchesne, 1937-80, vol. 10, col. 1984-85. 
selecionam e petrificam as variadas e dinâmicas narrativas míticas, ou através de fragmentos reunidos pelo folclore. No primeiro caso, temos por exemplo a mitologia grega tal como a conhecemos hoje; no segundo temos as narrativas medievais, tão fortemente impregnadas de material folclórico, que as devemos considerar transmissões orais tanto quanto literárias ${ }^{(37)}$. Material que por sua própria característica revela sempre alguma descontinuidade cultural, seja de uma cultura em relação à outra contemporânea, mas estrangeira, seja à outra do mesmo espaço, mas de outro tempo, seja à outra afastada no tempo e no espaço, seja à outra do mesmo espaço e do mesmo tempo, mas considerada arcaica comparativamente aos valores da cultura que a observa.

Nesse último caso, o folclore torna-se cultura de contestação( ${ }^{(38)}$. Enquanto uma mitologia é conhecida e aceita por toda a sociedade, o folclore o é apenas por uma parte

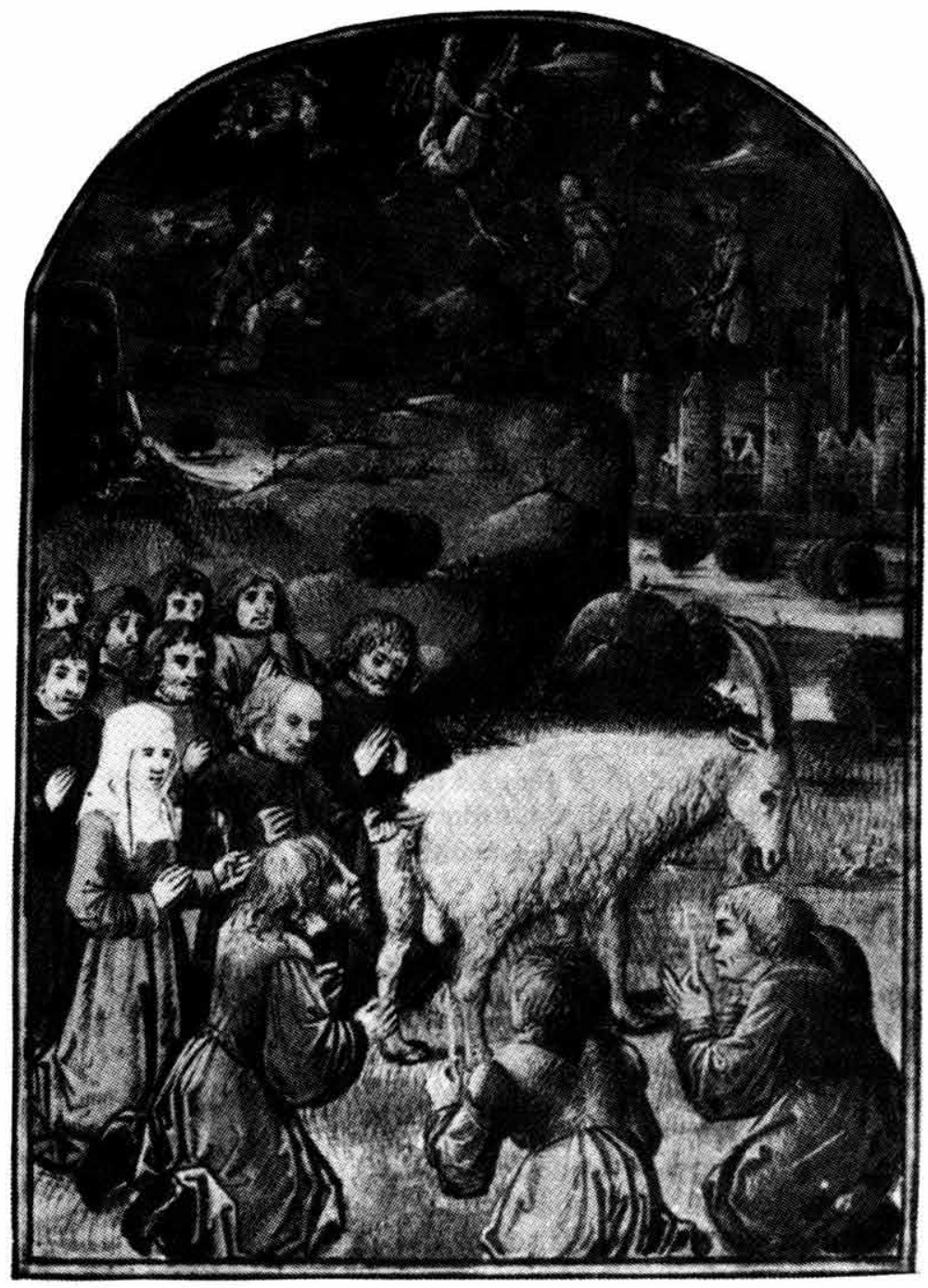
dela, aquela que por razōes históricas manteve-se ligada a certas tradições que foram sendo ultrapassadas para os demais segmentos sociais. Daí seu caráter contestatório. Caso da cultura laica dos séculos VIVIII estudada por Le Goff ${ }^{(39)}$, da dos séculos XII-XIII analisada por Koehler ${ }^{(40)}$, da campesina dos séculos XVI-XVIII vista por Mullett ${ }^{(41)}$. Essa cultura folclórica é sem dúvida de fundo mítico, apesar de ter sido modificada ao longo do tempo pela transmissão anônima e oral. Mas não se trata de degeneração nem de sobrevivência, como pensavam os primeiros folcloristas, mas de material selecionado e adaptado a contextos históricos diferentes daqueles que viram a formação de suas mitologias. Folclore é uma mitologia residual.

Para Jean-Claude Schmitt, contudo, a cultura folclórica medieval era algo diferente de uma mitologia. Para ele os mitos semíticos do Genesis legados pela Biblia ao cristianismo medieval "não eram mais vividos como tal", porque explicados pela Igreja tinham-se tornado história, a história sagrada. Como a cultura clerical tirara da cultura folclórica o saber por excelência (o conhecimento do Além, a comunicação com os seres sobrenaturais, a interpretação das visões), "vê-se mal como o folclore medieval teria podido falar por mitos, pois é função dos mitos constituir e transmitir um tal saber"(42). Ora, o fato daquela cultura ser "folclórica", isto é, contestatária, indica que a cultura clerical não privara totalmente a cultura folclórica de suas funções, daí a própria existência desta e a possibilidade dela exercer uma resistência, uma contestação.

Frontispicio da traduçáo

francesa do Tratactus

contra sectum

Valdensium, de Johannes

Tinctoris
A prova - para argumentar com o primeiro ponto lembrado por Schmitt - temos no fato de, paralelamente ao relato bíblico genésico, o Ocidente medieval ter conhecido pelo menos quinze textos considerados apócrifos que tratavam essencialmente dos mesmos temas. A Igreja exercia naturalmente certo controle sobre o texto canônico, ainda que não tão grande quanto se poderia pensar à primeira vista, devido aos meios limitados de que dispunha em grande parte da Idade Média, com um clero paroquial de forma geral mal preparado e muitas regiões superficialmente cristianizadas. Assim, os textos apócrifos na sua variedade e maior plasticidade mantinham viva a explicação mitológica das origens. O mesmo, é claro, ocorria em relação aos outros textos bíblicos. Quanto ao segundo ponto, a indicação de que a cultura folclórica não perdera "o saber por excelência" está nos inúmeros relatos de viagens ao Além e de interpretação de visões, que mesmo clericalizados escondem mal seus fundamentos míticos. Ou seja, o folclore falava através de mitos (ou de fragmentos destes) simplesmente porque estes são o 
material constitutivo daquele(43).

É verdade que logo a seguir aquele grande historiador matiza sua posição e coloca a questão: "Nas margens internas do cristianismo, onde se misturavam folclore e heresia, onde a atuação da Igreja era menos forte, é impossível que o Ocidente medieval tenha também ele conhecido o mito?". Naturalmente a resposta, contida na própria pergunta, é não. Contudo, trata-se de uma afirmativa demasiadamente cautelosa. Se lembrarmos do "pensamento mítico" de que estão carregadas diversas formas narrativas (lendas, contos, exempla, etc.) utilizadas pelos clérigos medievais, seremos levados a considerar que não apenas "nas margens internas do cristianismo" a Europa medieval conheceu mitos. Sobre esse ponto, portanto, é preferível acompanhar Jean Seznec, para quem a mitologia sobreviveu na Idade Média “em diferentes níveis, e antes de tudo no folclore'(44).

Se as considerações anteriores são de forma geral válidas para o estudo de sociedades pré-industriais, o caso das sociedades ocidentais contemporâneas economicamente desenvolvidas apresenta características próprias. Lembremos apenas, de passagem, que nelas se quebrou a relação dialética entre mito e rito, gerando crise de identidade, de desagregação e de angústia. Com ausência de mitos - fatos e personagens assim chamados nas sociedades industriais ou semi-industriais são construções da mídia, substitutos caricatos e efêmeros dos mitos no seu significdo coletivo, especulativo, inconsciente os ritos se esvaziam. Tornam-se atos, gestos e palavras repetidos por modismo, fabricados e consumidos como fonte de prestígio social, de certa identidade grupal, diferentemente das sociedades arcaicas, nas quais eles regulam as tensões, canalizam a violência. Pois rito é sacrifício. O sangue derramado ritualmente impede (ou minimiza) o derramamento cotidiano ${ }^{(45)}$, como ocorria por exemplo na sociedade asteca ou na sociedade cristã tradicional.

Sem dúvida o auto-sacrifício de Cristo pelos homens, prolongado na comunhão, afastava-se do sacrifício de homens aos deuses astecas. Mas na aculturação que acompanha a conquista espanhola do México, em nome do cristianismo - o que não era simples máscara de interesses econômicos como pensam alguns: a globalidade histórica tende a ser menosprezada por certas análises fragmentárias - se derrama sangue "pagão" para glória da divindade “cristã”. Para sobrevivência da sociedade, enfim. E desta forma as duas culturas se aproximavam no essencial. Na verdade aquela guerra, como todas as guerras, como todas as festas, mostraram Huizinga e Caillois ${ }^{(46)}$, era o encontro de dois mundos, superior e inferior, divino e humano. Pois festa é momento de regeneração do tempo, de volta ao caos simbólico, de suspensão temporária das normas sociais, por isso historicamente momento em que ocorrem sublevações. Mas nas sociedades contemporâneas ela não é tanto uma reenergização do tempo, quanto uma pausa para reenergização do homem. Que retorna depois ao trabalho mais produtivo e menos integrado ao cosmos, e porque menos integrado ao cosmos, mais integrado ao trabalho.

Todas essas violências da sociedade industrial a processos psicológicos e antropológicos enraizados profundamente há milhares de anos é que levam ao ressurgimento do misticismo. Pois fenômenos místicos são fórmulas culturais de busca de conhecimento, de revelação, de desvendamento do oculto: mystikós, "relativo aos mistérios", deriva de mystérion, “iniciação”, “saber reservado aos adeptos”. Logo, porém, na lógica da contemporaneidade, aqueles fenômenos são banalizados e não chegam a cumprir seu papel. São transformados em best-sellers, em modismos, em espetáculos. Um momentochave para a sociedade e a religiosidade arcaicas como o Carnaval(47) perde em espontaneidade para ganhar em colorido, perde em comunicação cósmica para ganhar em comunicação televisiva. Pobremente místicas, essas manifestações são descartadas e substituídas por outras, que alimentam mal muitos espíritos e alimentam bem poucos bolsos.

A aparente democratização da informação esconde forte centralização dela, dominada por alguns particulares em certos países, pelo Estado em outros; a aparente variedade de opções em algumas sociedades esconde uma uniformização de conteúdo. Na aldeia global da comunicação de massa, ao sabor dos interesses em jogo, as identidades culturais são - ou quase - anuladas, ou artificiaimente alimentadas. Nesse quadro, o encontro de cada um com seus deuses internos - sentido etimológico, cultural e psicológico do grego enthousiasmos - se dá pelas drogas, o sucedâneo atual mais próximo dos veihos ritos. Contudo, contrariamente àqueles, elas se revelam frágeis e fragilizadoras, pois não estão fundadas em mitos, em verdades profundas para o conjunto da sociedade. São válvulas de escape de uma minoria. Assim, paradoxalmente, em todos os sentidos, nunca a chamada cultura popular foi tão de elite, e quase é esquecido que no passado, em maior ou menor medida, com maior ou menor consciência, o "povo" eram todos.
37 B. Rosenberg, "Folkloristes et Médiévistes Face au texte Littéraire: Problèmes de Méthode", in Annales E. S. C. 34,1979, pp. 943-55.

38 L. M. Lombardi Satriani, II Folklore come Cultura di Contestazione, Messina, Peloritana, 1966.

39 Cf. nota 24.

40 E. Koehler, "Observations Historiques et Sociologiques sur la Poésie des Troubadours", Cahiers de Civilisation Médiévale, 7, 1964, pp. 27-51; L'Aventure Chovaleresque. ldéal et Réalité dans le Roman Courtois, Paris, Gall mard, 1974.

41 Mullett, op. cit., cap. 3.

42 J.-C. Schmitt, "Christianisme et Mythologie. Cccident Médiéval et Penseee Mythique", in Bonnefoy, op.cit., I. 183-4.

43 E. M. Meletinsky, "Du Mythe au Folklore", in Diogène, 99, 1977, p. 120 N. Beimont, Paroles Paiennes. Mythe et Folklore, Paris, Imago, 1986, pp. 15 e 153 .

44 J. Seznec, op. cit, II, 128: La Survivance des Dieux Antiques, Paris, Flammarion, 1980.

45 Ver sobre estas consideraçð̄es o belo livro de F. Cardini, Dias Sagrados. Tradición Popular en las Culturas Euromediterraneas, Barcelona, Argos Vergara, 1984

46 J. Huizinga, Homo Ludens, São Paulo, Perspectiva: R. Caillois, L'Homme et le Sacré, Paris, Gallimard, 1950: Les Jeux et les Hommes, Paris, Gallimard, 1958.

47 J. Caro Baroja, Le Carnaval Paris, Gallimard, 1979; C. Gaignebert, Le Carnaval: Essais de Mythologie Populaire, Paris, Payot, 1979. 